\title{
Design of Smart Bio-Shed Using IoT with Raspberry PI
}

\author{
T. SR. CH. Murthy, SK. Nayab Rasool
}

\begin{abstract}
Wireless sensor Networks(WSN)are used in Agriculture sector to provide good production chain to meet the requirements of quality and precision.

This proposed system describes the development of smart Bio-shed using Raspberry pi and sensors. This system monitors the soil moisture content, water level, Animal detection in the crop, precision agriculture, water $\mathrm{pH}$ level and agriculture products storage. By using this proposed system, we can monitor and maintain the farm at any place in the world through the internet. We used different sensors in this system to monitor the crop. The microcontroller controls the whole system.

With the help of this system, modern technologies and new ideas can be implemented in the farm sector of our country. With the help of farming website, the farmer can monitor his farm at any place in the world. So that this system reduces the risks present in irrigation sector. This idea motivates the many entrepreneurs to invest in the agricultural sector.
\end{abstract}

Keywords: IoT, GSM, Soil-Moisture sensor, Wireless Sensor Network, Microcontroller

\section{INTRODUCTION}

This proposed system helps the farmer to control the motor and water to the fields and also helps to control the bio-shed based on the environment temperature. In this system we used five different sensors namely (Temperature Sensor, $\mathrm{pH}$ Sensor, Soil Moisture Sensor, PIR Sensor, and Rain Sensor). In this system, the bio-shed will be operated according to the atmospheric conditions. Whenever the temperature is normal the shed will be closed to give the plants normal conditions. When the temperature goes high the Temperature sensor will detect the temperature in degrees, then the controller makes the shed to open to protect the crop.

Heat sensor (Temperature sensor) will be interfaced to the Raspberry pi to monitor the environment temperature condition. Motor pump will be turned ON/OFF based on the environment temperature. A Shed will be operated according to the Temperature. LM3914 is used in this circuit to Control the whole System.

This proposed system helps the farmers to control the total farm using internet [8]. In this system, we used different sensors to detect different parameters like soil-moisture content, environment temperature, Rain fall intensity etc. In this system,we used GSM Module to give the alert message to the particular farmer [7]. All the changes in field can be managed with the smart mobile connected to internet.

Revised Version Manuscript Received on 10 September, 2019.

T. SR. CH. Murthy,Assistant Professor,Department of ECE, Anurag Group of Institutions,Hyderabad, Telangana, India.

(Email: murthytommandruece@cvsr.ac.in)

S K. NayabRasool, Assistant Professor, Department of ECE, Anurag Group of Institutions, Hyderabad, Telangana, India.

(Email: nayabrasoolece@cvsr.ac.in)

\subsection{IoT (Internet of Things)}

The Internet of Things (IoT) is the new technology that deals with the internetworking of physical devices, buildings, vehicles and other items-including embedded systems with actuators, sensors etc. The network connectivity enables these objects to exchange their data [8].

The Internet of Things (IoT)devices are designed for the usage of consumer, which includes Home automation, Irrigation sector, Healthcare systems etc.

In agriculture sector, there are many IOT applications. These are used to collect temperature data, soil moisture content, water $\mathrm{pH}$ level etc. This data is useful to the farmer to take necessary action and to improve the quality and quantity in agricultural sector.

\subsection{IoT Functional Blocks}

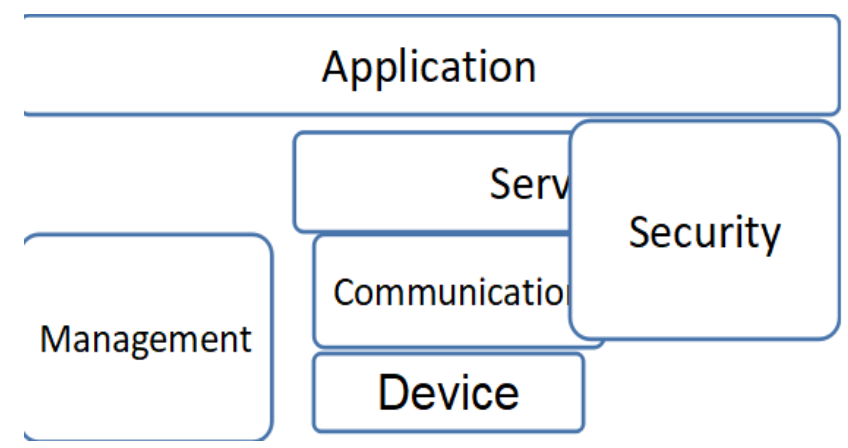

Fig 1: Functional blocks of IoT

\section{ARCHITECTURE OF PROPOSED SYSTEM}

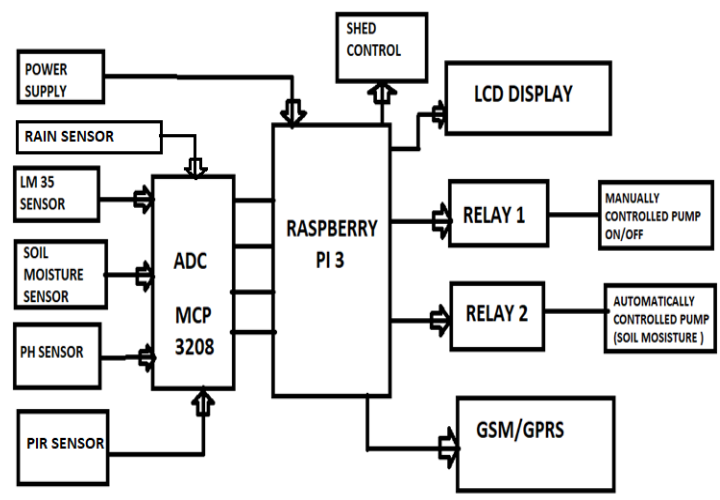

Fig 2: Proposed system Block diagram

In this proposed system, we used Raspberry pi3, Rain sensor Module, Temperature sensor (LM 35sensor), Soil moisture sensor, PIR sensor, Relay circuits, GSM module etc. The Rain sensor in this system measures the rainfall

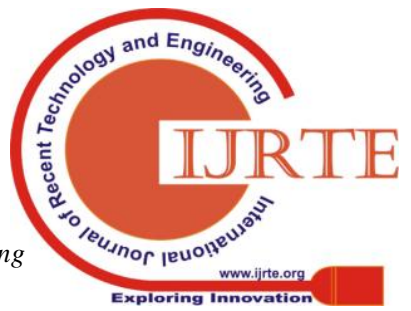


intensity and gives the information to the controller, which forces the motor pump turned OFF. The motor pump will turn ON/OFF based on the value obtained through Rain sensor Module.

The Temperature sensor detects the environment temperature in ${ }^{\circ} \mathrm{C}$, it gives the proportional voltage to the controller. If the temperature level is above the pre-defined level, the shed will be opened to provide shade [1]. The Soil-Moisture sensor used in this system detects the soil water content and it gives the proportional information to the controller. If the soil water content is low, the controller makes the motor pump $\mathrm{ON}$ and provides water to the crop [3].

The $\mathrm{pH}$ sensor used in the proposed system monitors the soil acidity and alkalinity. If the $\mathrm{pH}$ level is not within the specified range, it gives the alert message to the farmer. Then, the farmer can take necessary action. Ing gtg7his system, we used ADC (MCP 3208) to convert analog information into digital information. Relay circuits have been used to control the motor Pump.

The Shed will be operated according to the temperature, LM3914 is used in this circuit to Control the whole System.

This is an economical, convenient and reliable system. This system helps the farmers to save the time, energy and it can be managed with the smart mobile connected to internet.

\subsection{Raspberry Pi}

- Board size: --- $85.60 \mathrm{~mm}$ x $53.98 \mathrm{~mm}$

- Board weight -- $40 \mathrm{gm}$.

- PCB --- 6 layer PCB

- BCM2835 IC -- Broadcom BCM2835 (CPU + GPU + SDRAM)

The Raspberry pi is an ARM11 type microcontroller. It was developed by Broadcom company. Broadcom built this chip as a" processor for multimedia applications and also for embedded and mobile applications." the processor Speed is $700 \mathrm{MHz}$.

- SMSC LAN9512/LAN9512i IC---Ethernet Controller and USB Hub. The Raspberry pi board has inbuilt USB port to interconnect USB peripheral devices.and also for IP networking.This USB and Ethernet ports are used for serial communication.

- JTAG Header: The JTAG Header is available in Raspberry pi board to perform debugging operations such as Break-pointing and single stepping.

- CSI Camera Connector: The Raspberry pi board has CSI Camera connector.It is used to interface camera and host processor especially for mobile applications.

- DSI Display Connector: The Raspberry pi board has inbuilt DSI Display connector cable.It is used to interface mobile device display subsystems to the Raspberry pi board. Sometimes graphical LCD/LED displays are also attached to the board.

- Indicating LED's :- 5 no's of status indicating Light Emitting Diodes(LEDs) --

- D5(Yellow) - OK -indicates SD Card accessed (via GPIO16)

- D6(Red) - PWR - 3.3V Power

- D7(Green)-FDX-Supports Full Duplex communication (LAN) (Model B)
- D8(Green) - LNK - Shows the Link/Activity (LAN) (Model B)

- D9(Yellow) - 10M -It indicates the speed 10/100Mbit (LAN) (Model B)

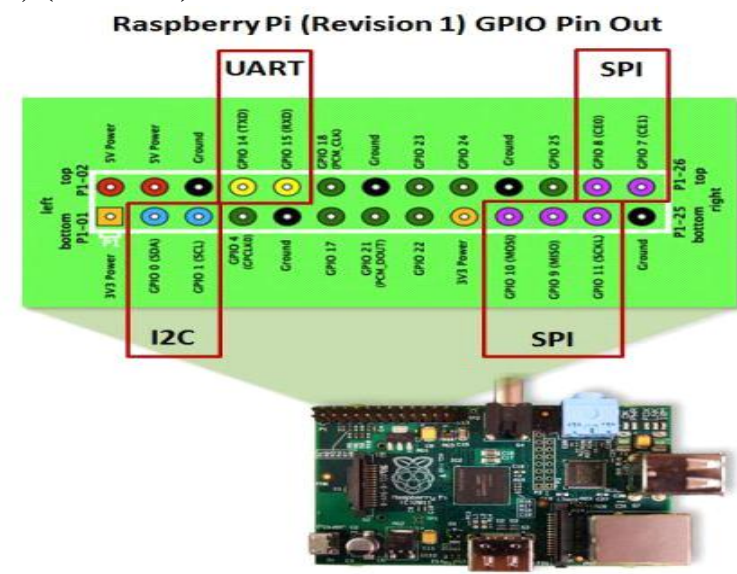

Fig 3: Raspberry Pi Pin Configuration

How to give Static IP Address to Raspberry Pi and access it using SSH on Ubuntun PC

- Burn the Raspbian image on the SDcard using ImageWriter software and using Ubuntu PC.

- Check SDCard (using card reader) on Ubuntu PC in home foler icon.

- You have observed that SD card having two partitions 1) Boot

2) File system or something like that

In the boot partition one file is available name as cmdline.txt. Open this file. We will see that something is already written in this file. Now add below line at the end, in this file and save it.

ip $=192.168 .3 .2$

- Insert SD card onto the raspberry pi board.

- Connect raspberry pi board and our Ubuntu computer using LAN (Ethernet cable).

- Open Terminal on Ubuntu pc and type

\$ sudoipaddr add 192.168.3.2 dev eth0

\# avahi-browse -rat --all

\$ sudosshpi@192.168.3.2

below message will apper --

Enter password for pi as raspberry:

Note - The default password is raspberry

- we will get raspberry prompt as,

- $\quad$ pi@ raspberrypi / \$ 


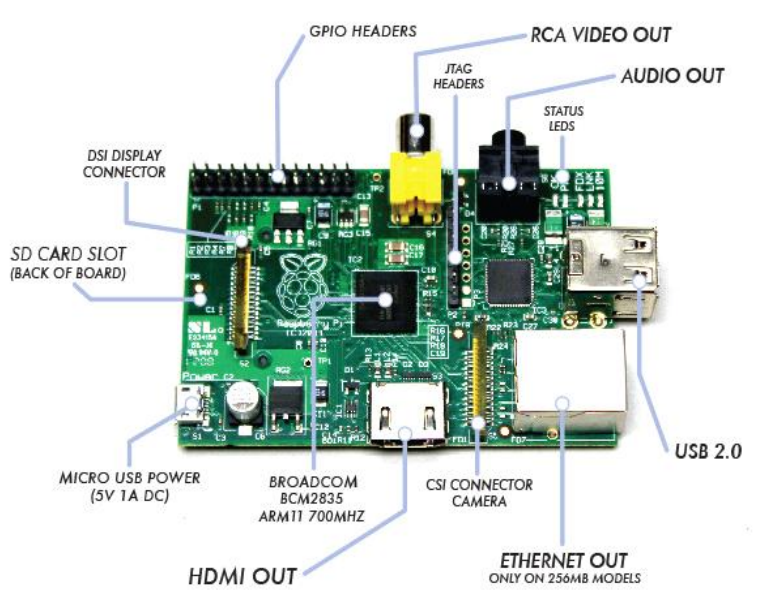

Figure4 : Raspberry pi Board

\section{LM35 SENSOR}

These sensors are available in Integrated circuit(IC) form. These sensors produce the output voltage which is linearly proportional to the Degree Centigrade temperature. But other type sensors are also available whose output voltage is linearly proportional to degree kelvin temperature.LM 35 Sensors requires single supply ranging from 4-30V.

The operating temperature range of LM 35 sensor is $-55^{\circ} \mathrm{C}$ to $150^{\circ} \mathrm{C}$. The $\mathrm{LM} 35 \mathrm{C}$ sensor operating temperature range is $-40^{\circ} \mathrm{C}$ to $110^{\circ} \mathrm{C}$.

\section{Features}

- Calibrated in Celsius (Centigrade)

- $+10-\mathrm{mV} /{ }^{\circ} \mathrm{C}$ linear Scale Factor

- $0.5^{\circ} \mathrm{C}$ Ensured Accuracy (at $25^{\circ} \mathrm{C}$ )

- Operating temperature range is $-55^{\circ} \mathrm{C}$ to $150^{\circ} \mathrm{C}$.

- It is suitable to use in Remote applications

- Low-Cost

- Operating Voltage range is $4 \mathrm{~V}$ to $30 \mathrm{~V}$
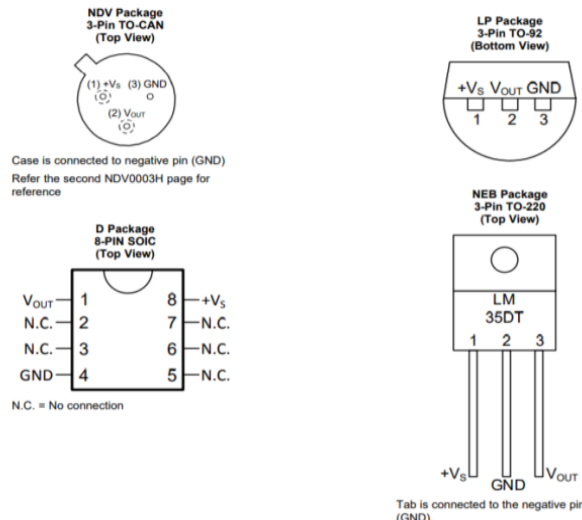

Figure 5 : LM35 Sensor pin configuration

\subsection{Soil Moisture Sensor:}

These sensors are used to measure the soil water content. The functionality of soil moisture sensor is described by the transistor current amplifier. If the water content in the soil is sufficient, some base current flows through the transistor which in turn generates the collector and emitter currents. Whenever emitter current flows through the emitter resistor, some voltage will be developed across the emitter resistor.
This voltage will be given to A/D Converter to get the value in decimal digits.

Features:

- Required supply voltage range is $2.0 \mathrm{~V}-5.0 \mathrm{~V}$

- Analog output facility is available

- Detectable depth is $38 \mathrm{~mm}$

- $20.0 \mathrm{~mm} * 51.0 \mathrm{~mm}$ Dimension size

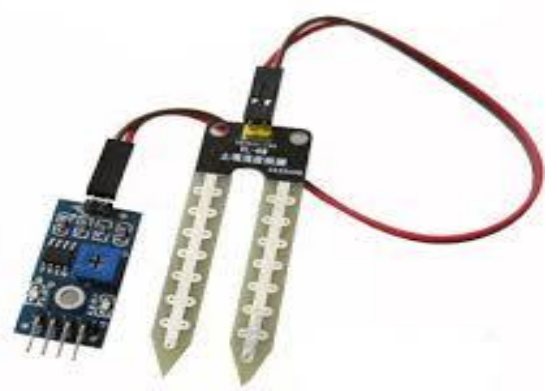

Figure 6: Soil Moisture Sensor

\section{Applications:}

This module is useful to design automatic plant watering system, soil moisture detection system, Automatic irrigation system etc.

\subsection{Pir Sensor:}

PIR sensor means Passive Infrared Sensor. These sensors are used to detect the human body movement within the sensors range. These devices are inexpensive and ready to use in required applications. These devices consume very less amount of power. So that these are commonly used in home appliances and in other electronic gadgets. These sensors detect infrared rays with wavelength range $8-14 \mu \mathrm{m}$ which is equivalent to the wavelength emitted from human body temperature.

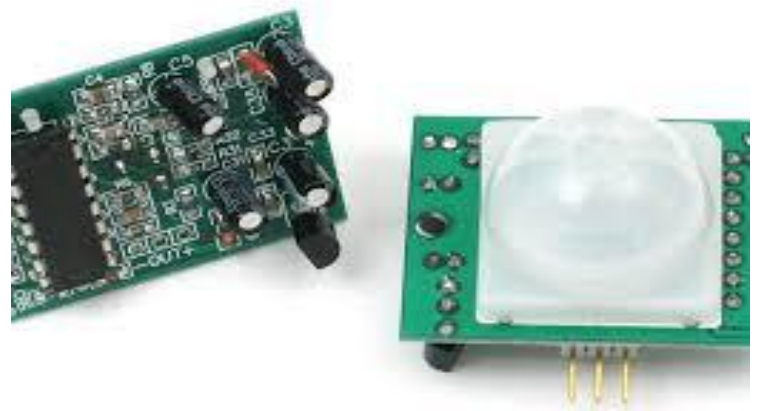

Figure 7: PIR Sensor

Features:

- Offers wide sensing area

- High Sensitivity.

- Required Supply Voltage is $5 \mathrm{~V}$.

- Delay Time Adjustment facility is available.

- Supports Standard TTL Output.

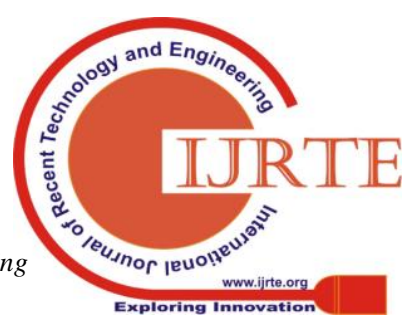




\section{3ph Sensor:}

\section{Ion selective field effect transistor}

An ISFET is an alteration of the typical field impact transistor utilized as a part of numerous speaker circuits. In the ISFET, the metal door, which is ordinarily utilized as data, is supplanted by a particle touchy film, the deliberate arrangement, and a reference terminal (as indicated in. In this manner, an ISFET joins in one gadget the sensing surface and a sign enhancer which delivers a high current, low impedance yield and permits the utilization of associating links without exorbitant protecting.

In this, we proposed to develop an in-situ soil $\mathrm{pH}$ sensor with Nano-particles of antimony ( $\mathrm{Sb}$ ) and zinc ( $\mathrm{Zn})$. This device overcomes the drawbacks present in existing systems. This device doesn't require separate power source. In this proposed system we used In-situ soil $\mathrm{pH}$ sensor. A conical shaped sensing electrode (A) interface with a reference electrode $(\mathrm{C})$ through the interfacing insulator (B).

The sensing efficiency of $\mathrm{pH}$ sensor depends on Nano-particle used in the formation of electrode.
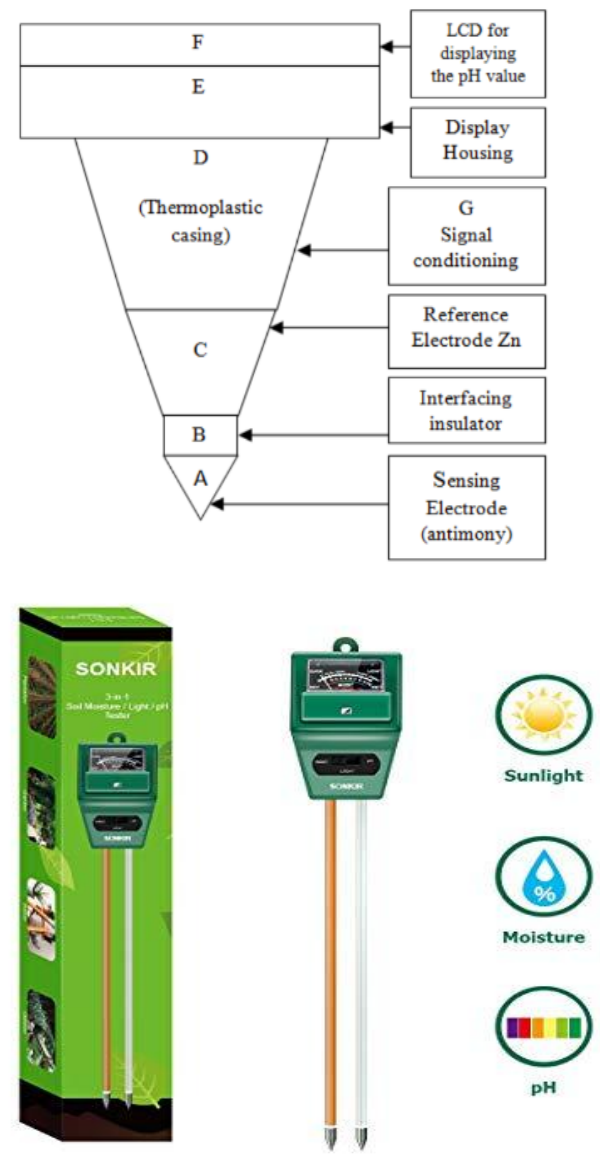

Figure 8: pH Sensor

\subsection{RAIN SENSOR MODULE}

This sensor is used to detect the rainfall intensity. This module consists of Rain board, Control board, power indicator and potentiometer for sensitivity adjustment. The analog output present in rain sensor module detects the amount of rainfall drops. If there is no rain drop, control board activates the DO output to HIGH. When rain drops are present on the rain board, the control board activates the DO output to LOW and also the switch indicator will turned ON.

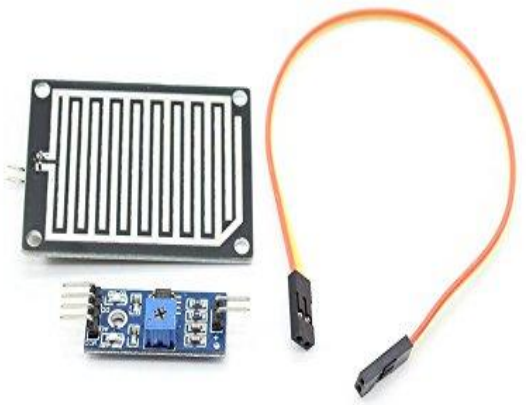

Figure 9: Rain Sensor

If we want to restore the device to initial state, We have to brush off the water droplets present on the Rain Board. This device requires $+5 \mathrm{~V}$ DC supply.

Pin Configuration:

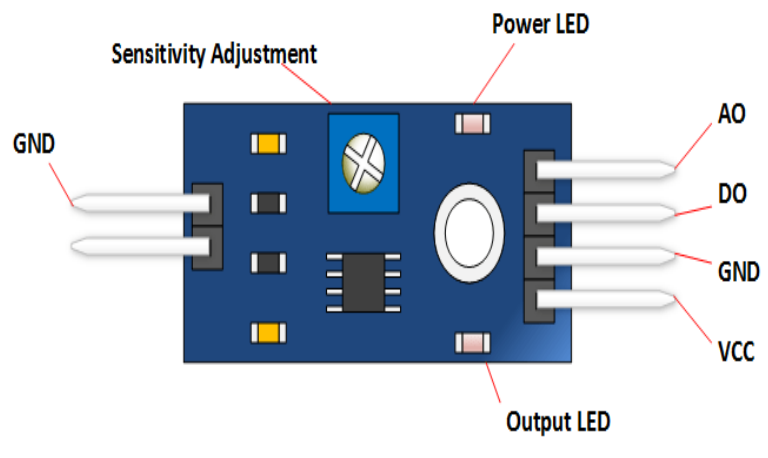

Figure 10: Rain Sensor Pin Configuration

\subsection{GSM Module}

GPRS refers to General Packet Radio Service. It supports the packet oriented data service for $2 \mathrm{G}$ and $3 \mathrm{G}$ cellular communication systems. Earlier developments were CDPD and i-mode packet switched data technologies. Later it was standardized by European Telecommunications Standards Institute (ETSI)and the name was GPRS. Now a days Third generation Partnership Project (3GPP) is maintaining this service

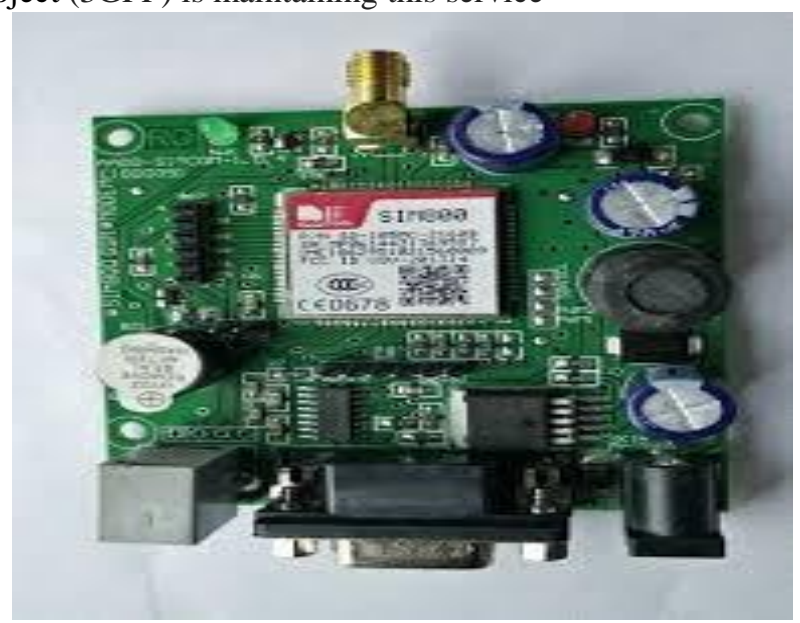

Figure 11:GSM module

Published By: Blue Eyes Intelligence Engineering 
The GPRS usage will be charged, based on the amount of data being transferred because it supports the packet-oriented data service. But in circuit switched data, the usage will be charged based on minutes of connection time [6].

GPRS also called as GSM-IP, i.e. Global System for mobile Communications Internet Protocol. This system keeps the users online. Which allows voice calls, Internet access etc.

In second generation systems(2G) GPRS provides the data rates range $56-114 \mathrm{Kbit} / \mathrm{second}$. The $2 \mathrm{G}$ cellular technology combined with GPRS, sometimes described as $2.5 \mathrm{G}$. i.e.it is a technology between second generation (2G) and third generation $(3 \mathrm{G})$ related to mobile telephony. It provides data transfer speed moderately, by using unused time division multiple access (TDMA) channels in.

GPRS offers higher data rate with shorter access time and easy billing. The GPRS system is an integrated part of the GSM network switching subsystem [3].

\section{Services}

GPRS extends the GSM Packet circuit switched data capabilities and supports the following services:

- $\quad$ SMS messaging and broadcasting facility

- $\quad$ "Always on" internet access

- $\quad$ Multimedia messaging service (MMS)

- Instant messaging and presence-wireless village

- Internet applications for smart devices through wireless application protocol (WAP)

The GSM/GPRS Module is an Integrated circuit which is interconnected to GSM network by using a SIM card. The GSM Module operates at the radio frequency range $850 \mathrm{MHz}, 1800 \mathrm{MHz}$ etc.

GSM Module features:

- Spectrum efficiency will be improved

- International Roaming facility is available

- Compatibility with ISDN (Integrated Services Digital Network)

- Good quality speech

- Supports SMS (Short Message Service)

- It has real time clock with alarm management system

\subsection{Buzzer}

Buzzers are used in electronic systems to produce the audio signal, i.e. Beep sound. These are used in Fire alarm systems, timer circuits, home appliances such as microwave ovens, game shows etc. There are many types of Buzzers such as magnetic buzzers, Piezo-electric buzzers and electromechanical buzzers. In this system, we used an electronic type of buzzer which is a piezoelectric element that is driven by micro-controller signals. The piezo electric buzzer is designed by placing two electrodes on the two faces of piezo electric material. When some voltage is given to these electrodes, the piezo electric material produces mechanical deformation. This movement produces sound wave in the buzzer circuit.

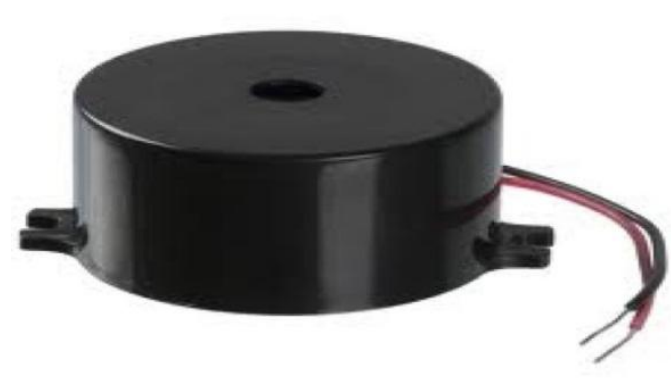

Figure 12: Buzzer

\section{RESULTS}

\subsection{Design Aspects And Approach}

\section{Algorithm}

STEP 1: Arrange the setup. Connect the proposed system to the power supply to get power $\mathrm{ON}$ for further steps to be carried out.

STEP 2: Then the system will initialize Raspberry Pi, GPRS module, LCD.

STEP 3: Once the Sensors are initialized, they sense the information and give it to the Processor

STEP 4: According to the information given by the sensors, Processor will perform necessary actions.

Step 3 and Step4 execute hand by hand.

STEP 5: Remove the setup from power connection after usage.

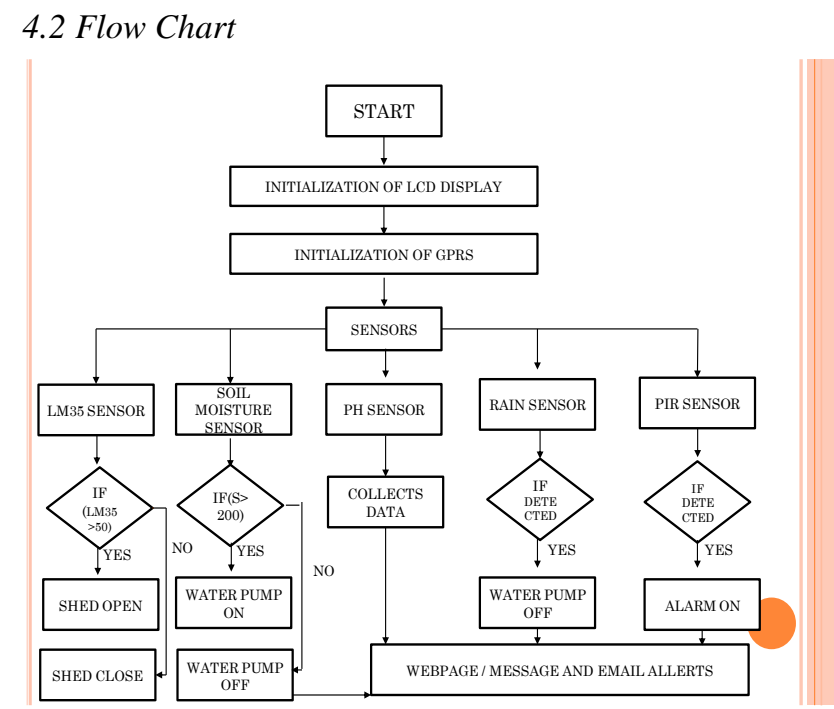

\section{Figure 13: Flow diagram of the proposed system}

\subsection{Test Setup:}

The setup consists of Raspberry Pi, GSM Module, LM35 Sensor, pH Sensor, PIR Sensor, Rain Sensor, Soil Moisture Sensor, Buzzer, LCD display (16*2), Power Supply Unit. All the components are interfaced to the Raspberry Pi board. These sensors data are monitored and given to Raspberry $\mathrm{Pi}$, where it performs certain operation and result is given through GPRS, buzzer, LCD. 


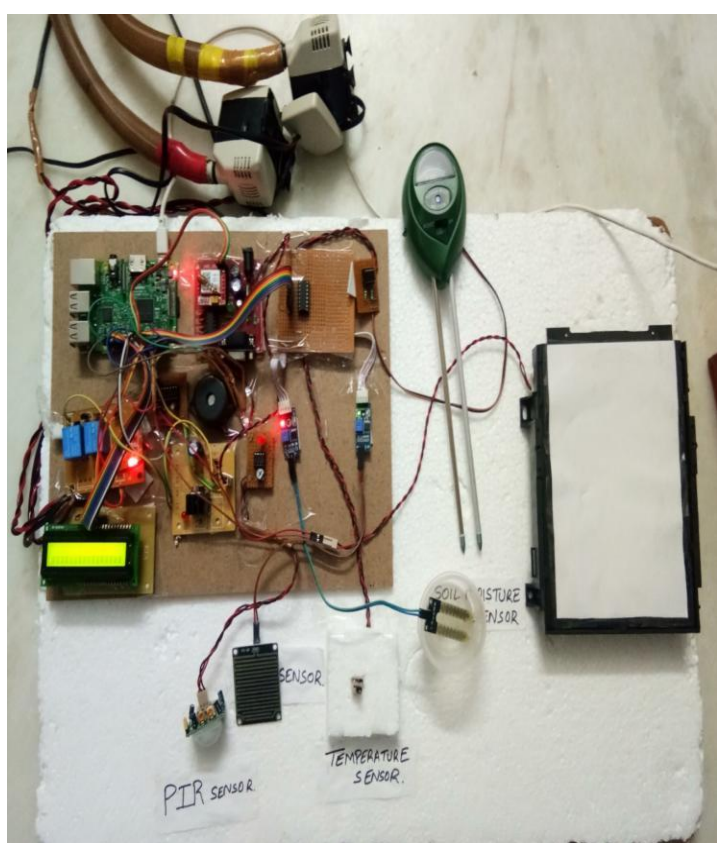

Figure 14: Test setup

\subsection{Test Results:}

The total process depends on 5 Sensors.

1). LM35 Sensor: When the temperature is increased above the critical value, then shed will be opened to provide shade.

2). Soil Moisture Sensor: When the soil water content is low, then the controller makes the motor pump turned ON and provides water to the crop.

3) Rain Sensor: The Rain sensor module detects the rainfall intensity. If this module detects the rain, to avoid wastage of water, the controller makes the motor pump turned OFF.

4) PIR Sensor: The PIR sensor detects the human body motion and it gives the Buzzer sound to the farmer to make sure that no animal damages the crop.

5) $\mathrm{pH}$ Sensor: This Sensor gives the information to the farmer about the crop fertility.

\subsection{Message Alerts:}

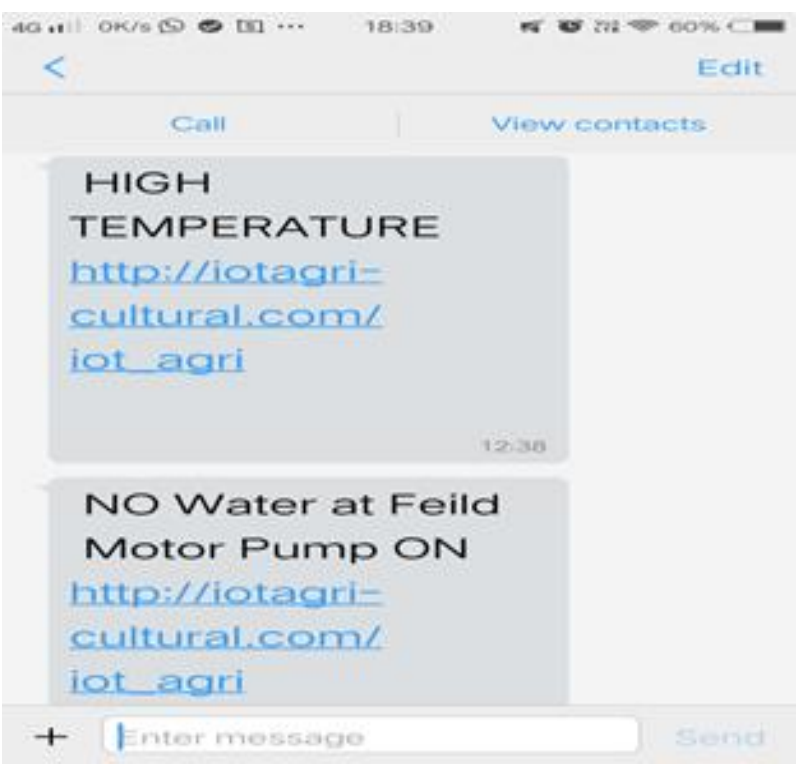

Figure 15: Message Alerts

4.6 Website:

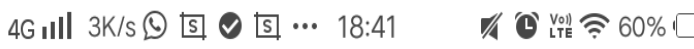

\section{仓 (i) iotagricultural.com/iot_ (110 :}

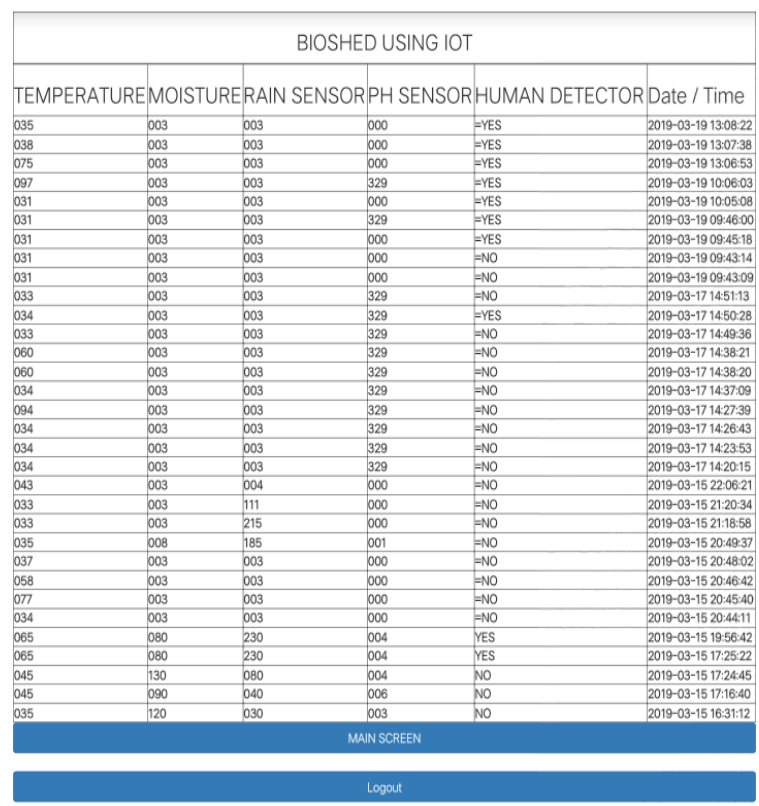

Figure 16. Website

Published By: 


\subsection{Email Alerts:}

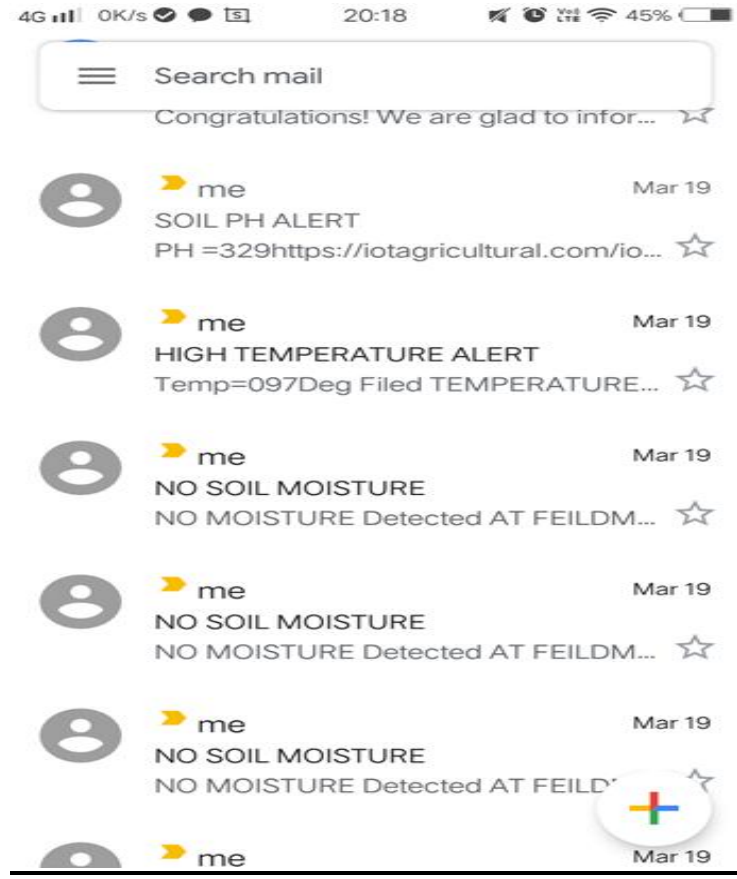

\section{V.CONCLUSION}

Hence, a smart Bio-shed is designed and implemented using Raspberry pi, GSM Module,LM 35 sensor, pH sensor,PIR sensor, Rain sensor, Soil moisture sensor etc. This proposed system is an economical and reliable compared to all other existing systems. This proposed system helps the farmers to control the total farm using internet. In this, we used different sensors to detect different parameters like temperature $\left({ }^{\circ} \mathrm{c}\right)$, soil moisture content, water $\mathrm{pH}$ level etc.In this system,we used GSM Module to get the alert message to the particular farmer. All the changes in the field can be managed with the help of internet. This system helps the farmers to save the time, energy and can be managed with the smart mobile phone with internet facility.

The Bio-shed present in the proposed system will be activated based on the temperature level. If the temperature exceeds the normal value, the shed will be opened to protect the crop. This innovative idea is a solution to the problems present in the existing irrigation systems.

\section{FUTURE SCOPE}

According to the BIS Research report ,the global smart farming market might be reached to $\$ 23.14$ billion by 2022 i.e.it indicates the annual growth rate of $19.3 \%$.

This market growth indicates, there is an increasing demand for agriculture production. Due to the wide developments of smart phones and internet of things (IOT) ,developed countries such China and Japan have already implemented these technologies in agriculture sector. The developing counties are also realized the need of these technologies in farming sector to meet the requirement of higher crop yield.

\section{REFERENCES}

1. I. Mampentzidou, E. Karapistoli, A.A. Economide, "Basic Guide-lines for Deploying Wireless Sensor Networks in Agriculture", Fourth International Workshop on
Mobile Computing and Net-working Technologies, pp. 864-869, 2012.

2. Herman Chung- HwaRao, Di-Fa Chang and Yi-Bing Lin, ?iSMS: An Integration Platform for Short Message Service and IP Networks?, IEEE Network, pp.48-56, March/April (2001).

3. ]S. Li, J. Cui, Z. Li, "Wireless Sensor Network for Precise Agriculture Monitoring," Fourth International Conference on Intelligent Computation Technology and Automation, Shenzhen, China, March 28-29, 2011.

4. Joaquín Gutiérrez, Juan Francisco Villa-Medina, Alejandra Nieto-Garibay, and Miguel ÁngelPortaGándara" AutomatedIrrigation System Usinga Wireless SensorNetworkandGPRS module" ,IEEE Transactions onInstrumentationand Measurement, Vol. 63, No. 1, January 2014.

5. MuhmadAzmanMiskam, Azwan bin Nasirudin, InzarulfaishamAbd. Rahim; "Preliminary DesignontheDevelopment of Wireless Sensor Network for Paddy Rice Cropping Monitoring Application In Malaysia";European Journal of Scientific Research ISSN1450-216X Vol.37 No.4, 2009.

6. Vijay Kumar Garg, Joseph E Wilkes, ?Principle and Application of GSM?,Upper Saddle River, NJ [u.a.]Prentice Hall PTR, pp. 177-192, 1999.

7. R.Suresh, S.Gopinath, K.Govindaraju, T.Devika, N.SuthanthiraVanitha "GSM based Automated Irrigation Control using Rain gun Irrigation System”, International Journal of Advanced Research in Computer and Communication Engineering Vol. 3, Issue 2,February 2014.

8. V.R.Balaji and M.Sudha, Solar Powered Auto Irrigation System" presented at International Journal of Emerging Technology in Computer Science and Electronics (IJETCSE), vol-20 Issue-2, Feb2016.

9. Archana and Priya ,Design and Implementation of Automatic Plant Watering system,Presented at "International Journal of Advanced Engineering and Global technology “, vol-04, Issue-01, Jan-2016.

10. P. B. Chikankar, D. Mehetre and S. Das, "An automatic irrigation system using ZigBee in wireless sensor network," 2015 International Conference on Pervasive Computing (ICPC), Pune, 2015, pp. 1-5. 